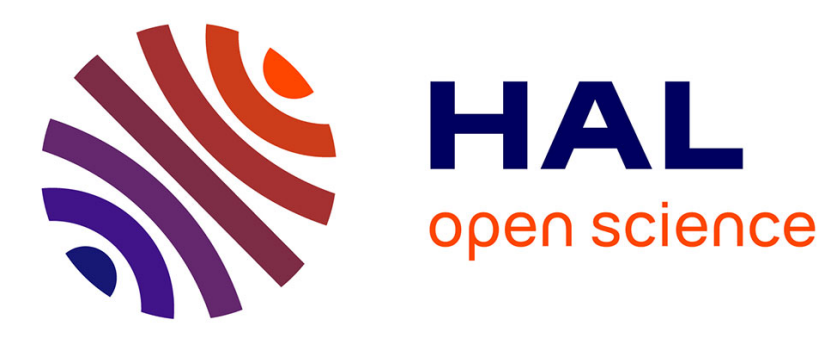

\title{
What is art? A methodological framework for a pluridisciplinary investigation
}

\author{
Alessandro Pignocchi, Alessandro Pignocchi
}

\section{To cite this version:}

Alessandro Pignocchi, Alessandro Pignocchi. What is art? A methodological framework for a pluridisciplinary investigation. Cognitive semiotics, 2009, pp.122-135. ijn_00643459

\section{HAL Id: ijn_00643459 \\ https://hal.science/ijn_00643459}

Submitted on 21 Nov 2011

HAL is a multi-disciplinary open access archive for the deposit and dissemination of scientific research documents, whether they are published or not. The documents may come from teaching and research institutions in France or abroad, or from public or private research centers.
L'archive ouverte pluridisciplinaire HAL, est destinée au dépôt et à la diffusion de documents scientifiques de niveau recherche, publiés ou non, émanant des établissements d'enseignement et de recherche français ou étrangers, des laboratoires publics ou privés. 
Cognitive Semiotics (2010)

WHAT IS ART?

A METHODOLOGICAL FRAMEWORK FOR A PLURIDISCIPLINARY INVESTIGATION

\begin{abstract}
Over the last decades, disciplines such as cognitive psychology, evolutionary psychology and the neurosciences have shown an increasing interest for art. It remains unclear what kind of relation these "young disciplines" should have with more traditional endeavors and, more generally, in which way they can enrich our understanding of art. In this paper, I lay down the foundations of a methodological framework which distinguishes between three basic topics: (1) the investigation of the cognitive phenomena elicited by the experience of things that we call 'artworks', (2) the investigation of the psychological structures determining the intuitive categorization of something as art and (3) the study of the intuitions and arguments used to build justifications about whether something is a work of art. Each of these topics can benefit from the cognitive approaches, provided that some specific methodological recommendations are respected.
\end{abstract}

\title{
1. Introduction
}

Over the last decades, "young disciplines", such as cognitive psychology, evolutionary psychology and the neurosciences (which I will group for simplicity under the label “cognitive approaches”), have shown an increasing interest for art (Dutton, 2008; Freedberg, \& Gallese 2007; Cavanagh, 2005; Ramachandran \& Hirstein, 1999; Zeki, 1999; Solso, 2005, 1994; Dissanayake, 1992). Art is certainly one of the most complex domains of human activity: it has a long and rich history, miscellaneous manifestations, intricate interconnections with many other human activities and, crucially, can mobilize nearly all kinds of human abilities and competences. Thus, we can surely welcome the fact that the theoretical investigation of art is now enriched by disciplines which give a new perspective - a naturalist perspective - on human abilities. Moreover, traditionally, the philosophy of art - a leading discipline in the theorization on art - has had normative ambitions (Schaeffer, 1992). The goal was, for instance, to find the right function of art, or the right way to interpret artworks. After 
the influence of Wittgenstein's Philosophical Investigations, some authors took a descriptive watershed (Weitz, 1956; Kennick, 1958; Dickie, 1969; Carroll, 1993; Schaeffer, 1996; Michaud, 1999; Gaut, 2000). They realized the importance of appropriate description, and the importance of clearly distinguishing description from normative discourse. The new aims were, for instance, to describe what people actually call 'art', or the way people actually interpret artworks. Cognitive approaches, as scientific approaches, can now help to accentuate this descriptive watershed. This is another reason to encourage cognitive approaches to integrate the ongoing reflection on art.

However, the kind of relation cognitive approaches should have with more traditional disciplines - such as philosophy, history, sociology or anthropology - and, more generally, the way in which they can enrich our understanding of art remains unclear (Walton, 2007).

In this paper I build the scaffoldings of a methodological framework with the aim of both clarifying what kind of contribution should be expected from cognitive approaches in a pluridisciplinary investigation of art and helping their positive interaction with traditional disciplines.

I will first identify two faux pas frequently committed by cognitive approaches of art - nonspecificity and essentialisation - which are responsible for some misunderstanding between the tenants of cognitive approaches and the tenants of traditional disciplines. I will then show that these faux pas can hardly be avoided without addressing, in one way or another, the question "what is art?". I suggest that behind this question there is a variety of different questions, and that distinguishing among these different questions is the first step towards a methodological framework for a pluridisciplinary investigation of art. Notably, it is essential to distinguish the questions which concern the properties of the things that we call 'artworks' (or the cognitive phenomena elicited by those properties) from the ones linked with the concept of art.

The main difficulty related to the inquiry into the properties of artworks consists in the fact that the set of things that we call 'artworks' does not constitute a natural kind with an associated set of necessary and sufficient properties. Thus, strictly speaking, there is no 'nature of art' to study. Therefore, it is necessary to question explicitly the nature of the fundamental aims of a cognitive approach of art, in order to understand how such approaches have to choose their objects of investigation.

The investigation of the concept of art also requires some methodological precautions. Notably, it is essential to distinguish between the intuitive categorization of something as art 
and the elaboration of reflective arguments and justifications to defend or reject the arthood of a thing.

The properties of artworks, the intuitive categorization of something as a piece of art and the reflective justifications concerning the arthood of a thing are three clearly distinct topics of investigation which are the armature of the methodological framework that I propose to endorse. As we shall see, the relevance of this three-stage distinction comes from the fact that for each of these topics, cognitive approaches of art have to respect particular methodological recommendations.

\section{Two Problems for Cognitive Approaches of Art: Non-specificity and Essentialisation}

The main faux pas of cognitive approaches of art is non-specificity. An approach of art is nonspecific when it investigates a property of some artworks (or a psychological or neural phenomena elicited by some artworks) which is also both shared by many things other than artworks and not shared by many other artworks. Since this property (or phenomenon) is neither necessary nor sufficient for something to be art, it is unclear how its investigation can enrich our understanding of art as art.

Ramachandran and Hirstein (1999) have spelled out a set of ten principles inspired, at least the most worked out, from the neurosciences, which supposedly help understanding the nature of art, or the nature of great artworks. The problem of non-specificity in their work arises from the fact that, as noted by Hyman (2006), many artworks fulfill only one or very few of these principles, whereas many things that are not art fulfill many of them if not all. As an illustration, consider the first principle, the peak-shift effect. Roughly, the claim is that artworks exaggerate some features used by the brain in object recognition. The perception of these exaggerated features hyper-activates the dedicated neural circuit which activates the limbic system, a system responsible for feelings of pleasure. For instance, the perception of a Hindu bronze sculpture of the divinity Parvati hyper-activate the neural circuit dedicated to the recognition of females' body, which explains the pleasure to look at it. This claim is nonspecific because (1) plenty of visual displays, the majority of which would not considered to be artworks, hyper-activate some neural circuit dedicated to object recognition (a smiley, for instance, certainly hyper-activates the circuit dedicated to the recognition of happy facial expressions), and (2) plenty of artworks do not exaggerate any features used for object recognition (for instance many artworks aspiring to naturalism, such as Constable's Wivenhoe Park, conceptual art such as Duchamp's Fountain, or minimalist artworks such as 
Malevitch's White Square on a White Square). The same kind of argument can be developed for all of Ramachandran's and Hirstein's principles.

As a consequence, it is not clear that these principles teach us anything specific about art. What is the difference, for instance, between claiming that some artworks fulfill some of Ramachandran and Hirstein's principles and claiming that some pieces of visual art activate the visual areas of the brain, or the visual area and the limbic system (claims for which nonspecificity is flagrant)?

In a similar vein, Freedberg and Gallese (2008) suggested that some pieces of visual art activate the mirror neurons system, either through their representational content or through the traces left by the artist's actions. Again, as noted by Casati and Pignocchi (2008), many things other than artworks activate the mirror neurons system, whereas many artworks presumably do not activate the mirror neurons system.

Another example is provided by Denis Dutton (2008), who proposes to characterize artworks with a cluster of twelve features inspired from evolutionary psychology, which shares some similarities with the set of principles spelled out by Ramachandran and Hirstein. Here also non-specificity is blatant because, as underlined by Casati (2009), many artworks possess only one or few of Dutton's features, whereas many things that are not art possess many of them.

The problem of non-specificity is not easy to deal with. In fact, the only way to solve it directly would be to look for a property or a psychological phenomenon that is characteristic of artworks. However, at least so far, no one was able to find such a property or phenomenon and, as I will explain in the next section, it is likely that none is to be found. Thus, on the one hand, we would want cognitive approaches to enrich our understanding of art as such and, on the other hand, it is possible that there are no properties or phenomena characteristic of art as such which could be investigated by cognitive approaches. Then, are cognitive approaches condemned to be non-specific?

In trying to address the problem of non-specificity, several authors made an even worse error, which brought to essentialisation.

Essentialisation is the arbitrary transformation of a descriptive claim (e.g. 'some artworks have the property P') into a normative claim (e.g., 'a thing must have the property $\mathrm{P}$ to count as real art'). Essentialisation appears, for instance, when an author investigates a property, or its cognition, and claims more or less explicitly that things that do not present this property are not art. Denis Dutton, in his book The Art Instinct, is brought to essentialisation when he claims that some pieces of minimalist conceptual art are not art (or very bad art) because they 
do not fit his own definition of art. Ramachandran's and Hirstein's rhetoric also contains traces of essentialisation, even if in a more implicit way than in Dutton's book. They claim that their principles characterize great artworks. Since all their principles describe ways to activate the limbic system, and since this system is responsible for feelings of pleasure, their theory implicitly contains the normative claim that a piece of art must be pleasurable to count as great art.

Notice that normativity as such is not a bad thing. As said in introduction, it has been the rule in many fields of the theorization of art. What is fallacious is to hide normativity behind professedly descriptive and scientific theories (the so-called 'naturalist fallacy'). Thus, as scientific accounts, cognitive approaches have to avoid any form of normativity. Of course it is always possible to use the results obtained by a cognitive approach to build a normative discourse about art. But in this case, normativity has to be very explicit, and clearly distinguished from the objective description and explanation of facts provided by cognitive approaches.

Thus, the first question to be addressed to improve our understanding of the way cognitive approaches of art should proceed is: how can the problem of non-specificity be avoided without falling in essentialisation?

This question is not an easy one, since, in order to be specific, it seems that it is necessary to find, first, what is specific to art; in other words, the above question forces us to address the question of what is art?

\section{What is Art? Artworks and the Concept of Art.}

As said, no one has found, so far, a property or a phenomenon necessary and sufficient for something to be art. It would be pointless, thus, to try to answer this question here. However, as we shall see, discussing this question and, more precisely, specifying what is problematic about it, helps finding a way to avoid the problem of non-specificity.

One thing, among many others, which explains the difficulty of the question 'what is art?' is that it hides a variety of different questions.

First, the question 'what is art?' can be a question about the properties of artworks and the way we cognize them, or a question about the concept of art. Focusing on some properties of artworks is quite a different thing than studying the concept of art.

To clarify this distinction between an object and a concept, consider the concept 'water'. It is clear that studying the physico-chemical properties of water is completely different from studying the way people identify, conceptualize and talk about 'water'. The physico-chemical 
properties of water is research topic for physics and chemistry, whereas the concept of water as it is commonly used is a topic for disciplines such as sociology, psychology, anthropology or history. For art as well, questions about the properties of artworks have to be clearly distinguished from questions about the way people use the concept of art in their thought and conversation about art or in their interactions with artworks.

We are strongly inclined to understand the question “what is art?”, or "what is water?” as a question about the objective properties of the object, not about the way people use the concept. For water, this is not a problem, since there is a natural kind - the things composed by molecules of $\mathrm{H}_{2} \mathrm{O}$ - the members of which share a set of characteristic properties independent of what people call water, and which coincides more or less with it. Moreover, we willingly accept that what science says about the things composed by molecules of $\mathrm{H}_{2} \mathrm{O}$ has a priority over what people call "water”. For instance, if someone calls “water” something that is not composed of $\mathrm{H}_{2} \mathrm{O}$, we are naturally inclined to accept that this person makes a mistake. For art things are more complex.

The concept of art has a quite complex history during which its use in language has changed very significantly. For the Greeks, the word 'art' was only used to refer to practices that required a high level of skill (e.g. the 'art of medicine' or the 'art of soldiering' (Carroll, 1999)). The Greeks already had a set of practices that we call art today (sculpture, painting, poetry...) but they had no unifying concept for them. The unification of the different practices that we consider today as paradigmatic of art occurred only in the eighteenth century with the publication of The Fine Art Reduced to a Single Principle by Charles Batteux. According to this author, painting, poetry, music, sculpture and dance must be unified under the common concept of 'Fine-Art' because they all share a common function: the imitation of the beautiful in nature. It is not clear whether this principle could unify these different practices as suggested by Batteux (for a discussion, see Carroll, 1999). In any case, the evolution of art after the eighteenth century has quickly and largely exceeded the function assigned by Charles Batteux. Artists have produced many artworks that were clearly not designed to imitate beautiful natural things. Nevertheless, the theory of Charles Batteux significantly influenced the work of artists, the way people thought about art, as well as the theoretical work about what art is. Other theoreticians argued that the theory of imitation was wrong, and proposed alternative unifying principles (the possession of significant form (Bell, 1915), the expression of artist emotions (Tolstoi, 1899), the clarification of its feelings (Collingwood, 1938) or the function of eliciting an aesthetic experience (Beardsley, 1983)). Again, it was soon acknowledged that, despite the attractiveness of those theories, none of them was able to 
capture the ensemble of things that people considered as art. However, again, those theories influenced the works of artists and the way people thought about art. These evolutions inspired other theoreticians, who elaborated even more powerful theories about the nature of art (such as the theory of embodied meaning (Danto, 1981) or the institutional theory (Dickie, 1969)). As their predecessors, those theories failed to capture the ensemble of things that we commonly call art, but they inspired artists and audience.

As shown by this extremely simplified history of the concept of art, what is considered as 'art' at a given historical period is a function of what was considered art at a preceding period, and the driving force of this evolution is a complex interaction among theoreticians, artists and audience (for a development of this argument see Weitz, 1956; Kennick, 1958; Levinson, 1979; Carroll, 1993). As a result, for the case of art, contrary to water, there is no natural kind, with a set of unique and characteristic properties independent of what people consider as art, and which coincides more or less with the set of things that people call art. Neither is there a natural kind for which science would have the same sort of natural legitimacy to claim that this and only this is real art, as it has in the case of water. Of course, it is possible to isolate a subcategory of things with a set of common and characteristic properties (having certain formal, expressive or semantic properties, for instance, or activating the limbic system) and claim that only those things are 'real art' and that people who call art things that do not share those properties make a mistake. But this move is what I have called essentialisation. In fact, this kind of claim is necessarily purely normative, since it necessarily excludes from the category of art things we commonly consider as art, and includes things we are not used to consider as art. Again, this kind of normative move can be interesting, but since it is normative, it is not appropriate for cognitive approaches.

Maybe the problem can be solved by claiming that art is simply what we call art, and by investigating the properties of these things. This move has two problems, however. First, the set of things that we call 'art' has extremely fuzzy boundaries because of important individual, social and cultural variations. Secondly, it does not solve the problem of nonspecificity, since the things that we call art do not share any characteristic properties.

Two reactions to this conclusion are possible. The first is to explicitly abandon the idea of studying a property which is specific to art and reconsider the goals of cognitive approaches, in order to understand how the objects of investigation of such approaches have to be isolated, given that the characterization of the nature of art, in a strict sense, is impossible. The second possible reaction is to study the concept of art itself, asking questions such as: how do we use it? How is it possible that, despite the fact that it does not refer to a natural kind, we 
understand what we are saying, at least to some extent, when we speak of 'art'? What determines the intuitive categorization of an object as art? What determines the kind of arguments that we use to argue for the arthood of an object? These two possible solutions to the problem of non-specificity are the topic of the next two sections.

\section{What is 'Relevant' for a Cognitive Approach of Art?}

The major conclusion of the last section is that cognitive approaches have to give up the ambition of investigating a property or a phenomenon that would be, strictly speaking, specific to art, because art is not a natural kind with a set of characteristic and unitary properties which could be an object of scientific investigation. Any property or phenomenon which could be studied by the cognitive approaches will be at best a feature of some, but not all, artworks, and will always be a feature of things that are not art. However, among the set of properties or phenomena which are shared by some artworks, not all seem to have the same degree of relevance for our understanding of art.

The capacity to activate the visual areas of the brain, for instance, or the capacity to activate the color perception areas, is a property which is shared by many artworks. However, the study of these properties does not seem to be relevant for our understanding of art. Then, what properties are 'relevant' for a cognitive approach to art?

To answer, it is necessary to notice that, contrary to the study of quantum mechanics, for instance, or of other areas of fundamental research, art is a domain that is strongly intertwined with our ordinary life. We interact daily with artworks, we think about them and we have conversations about them. Thus, what we expect from a cognitive approach of art - or from any theoretical approach of art - is that it could, directly or indirectly, enrich our real relations with art, i.e. enrich our interactions with artworks and the way we are able to think and speak about artworks and art.

Therefore, two constraints determine the kind of properties or phenomena that are 'relevant' for cognitive approaches of art. On the one hand, of course, they have to be potential objects of scientific investigation. This excludes, as I have shown, art as such, since the concept of art does not refer to a set of things with common and characteristic properties which could be investigated scientifically. For the same reason, it is likely that this first constraint also excludes very general and undefined topics such as aesthetic experience, the value of art, or the nature of great artworks. On the other hand - and this second constraint is quite unusual for a scientific approach - the topic of investigation must be connected with questions and theories that have the power of enriching our real and ordinary relations with art (our 
experience of some artworks, the way we reflect on them, the way we can speak of them...). This excludes very circumscribe properties or phenomena, such as the activation of visual areas or the perception of color (see Casati, 2003 for a similar point). In other words, it is necessary to find what Casati and Pignocchi (2008) called 'mid-level hypotheses', i.e. the hypotheses which are sufficiently circumscribed to be object of scientific investigation and, at the same time, sufficiently connected with our real relations to art.

One method to find this kind of hypotheses would be to take inspiration from theories developed by 'traditional' disciplines, such as philosophy of art or history of art, which are, at least some of them, explicitly concerned with the potential enrichment of our real relations with artworks (Baxandall, 1985; Wollheim, 1987). Generally, these theories are not concerned with the constraints of finding objects of scientific investigation. Thus, the method consists in isolating in these theories the points or questions which satisfy the constraints of scientific investigation in order to enrich, precise or improve the overall theory, which itself has the potential to enrich our relations with art.

Examples of mid-level hypotheses could possibly be found, for instance, in theories concerned with artist's intentions and the role played by their retrieval in our understanding and appreciation of an artwork. On the one hand, the causal role of intentions on behavior and the way we retrieve the intentions of an agent on the basis of observable cues is now a standard topic for disciplines such as cognitive psychology or neuroscience (for a review see Frith \& Frith, 2006). On the other hand, many very influential theories in philosophy of art (Levinson, 1979; Danto, 1981; Wollheim, 1987) and in history of art (Baxandall, 1985) are based on the concept of intention. Moreover, at least some of these theories are explicitly concerned with topics directly connected with our everyday relations to art ('what role could or should play my knowledge of the artist's intention on my interpretation and appreciation of an artwork?', for instance, is a question that any person who is even a little interested in art has asked). Thus, it seems likely that there are some hypotheses concerning artist's intention which would satisfy the two constraints discussed above (other examples of mid-level hypotheses can be found in Cavanagh, 1999; Casati, 2003 and Pignocchi, 2010).

A first step in the cognitive investigation of the artist's intentions and their retrieval would be using the concepts of cognitive psychology to provide a taxonomy of the different kinds of intentions which play a role in the production of an artwork, such as 'meta-cognitive intentions' (the intention that a property of an artwork will be perceived as being produced with the intention to elicit a given effect), 'simple propositional intentions' (the intention to elicit a given effect) and 'intentions in action' (the intentions which represent a given goal in 
the format of concrete actions), as well as a taxonomy of the different kinds of mechanisms used to retrieve these different kinds of intentions (inferential and simulationist mechanisms, for instance) (for an example of a cognitive approach of artist's intentions see Rollins, 2003 and Pignocchi, 2010).

As an illustration, consider the painting Woman taking Tea from Chardin. If we are asked about the intentions of the painter, our first spontaneous answer could be, for instance, that Chardin wanted to evoke a certain feeling of loneliness mixed with a subtle kind of melancholy. But this is only one (hypothetic) state of mind which could have determined the aspect of the painting. For the painting to be completed, nearly any Chardin's gestures had to be caused by a complex and organized set of intentions, ranging from the most abstract, such as the ones mentioned above, to the most concrete visuomotor planning of actions, such as the simple white brush stroke thanks to which he evokes the reflection of light on the teapot.

In order to bridge the gap between very abstract intentions and very concrete gestures, Baxandall (1985) has described the influences exerted on Chardin by the scientific theories of visual perception of his century. The main topic of these theories, inspired by Locke and Newton, was to investigate the active role played by the subject during perception. According to Baxandall, Chardin toke inspiration from some principles of these theories in order to create a set of complex perceptive effects. Notably, he blurred the contour of the face, because he knew that faces strongly attract attention, and he did not want that the observer could stabilize his attention on a single point. To counterbalance the attraction of the face, he also created an area running from the nape to the hand holding the cup, on which attention has multiple attraction points created either by contrast, luminosity or clearness. He further destabilized perception by creating conflicts between linear perspective and various principles describing the role played by colors on illusions of size and distance. He also played in multiple ways with the principle according to which acuity diminishes from the fovea toward the borders of the visual fields. The intentions connected with the use of all these principles are of course organized inside more abstract plans, concerning properties of the general experience elicited by the painting.

To recover the different kinds of intentions involved in the production of Woman taking Tea, we use very different kinds of psychological mechanisms. To retrieve very abstract intentions we possibly use inferential processes which are quite automatic for many of us, possibly because we are culturally trained to understand painting in this way (Schaeffer, 1992). Instead, when we pay attention to the brush strokes we possibly activate a motor simulation of some aspect of Chardin's gestures. When we think about the influence of the scientific 
theories of visual perception we need to make an effort to put us in the shoes of a painter of the eighteen century who is impressed by the progress of science and who wants to play with scientific principles. We also recruit inferential mechanisms to understand, for instance, whether Chardin wanted the spectator to recognize that he used the contemporary scientific theories of vision or if he just wanted to use these theories to produce certain effects.

All this is exaggeratedly simplistic of course, and much more work is needed to come up with a plausible scenario of the intentional process of creating Woman taking Tea (a process that we experience, whatever our knowledge, as highly coherent) and to describe possible psychological mechanisms used to recover it. More work is needed also to show that it is possible to draw the contour of a general taxonomy of the different kinds of intentions involved in the production of an artwork and of the psychological mechanisms used to recover them. The point here is only to show that this topic could possibly fulfill the two constraints: being a potential object for science and being able to enrich our real relations with art.

Let us now move to the other possible answer to the problem of non-specificty: the investigation of the concept of art.

\section{Intuitive Categorization and Justification}

Here also, some key distinctions have to be drawn, since it seems unlikely that there is such a thing as the concept of art, which could be a single and clearly defined object for science. In order to draw the relevant distinctions, it is useful to take inspiration from the field of ethics, where the cognitive theories are more advanced than in the field of art. In the psychology of morals, one of the most basic distinction which frame the field differentiates between moral intuitions and moral justifications. Moral intuitions are what determine our first and spontaneous answers to questions of the kind “is this behavior moral or immoral?”. Moral justifications are what we say when we are asked to provide justifications for our answer. It has become clear by now that moral intuitions and moral justifications are determined by distinct psychological mechanisms, and it is frequent that when asked for justification we end up contradicting our first intuitive response (Green \& Haidt, 2002; Hauser et al. 2007; Green et al., 2008).

In the case of art, the very same distinction can be drawn. The object of the first level of investigation would be the mechanisms which determine our intuitive and spontaneous categorization of something as art. The object of second level of investigation would be the 
set of arguments and justifications that we build when asked to justify our spontaneous categorization of X as art or as non art (or as art "to some extent”, or as art "in a sense”, etc.) At the first level, a very simple protocol to begin the investigation of the mechanisms responsible for the intuitive categorization of something as art would simply parallel the one used to investigate moral intuitions. It would consist in asking subjects to answer questions such as “is X an artwork?” where X is either a real object or a fictive one constructed for the purpose of the design. The aim would be to connect the investigation of the intuitive use of the concept of art with the existing psychological literature on the concepts of artifacts (e.g. Bloom, 1997; Casler \& Kelemen, 2005; Malt \& Sloman, 2007) and to clarify the possible specificity of the intuitive concept of art. Here also, a possible close collaboration with traditional disciplines, such as analytic philosophy of art, has to be envisaged. In fact, in the analytic philosophy of art there is a long tradition of designing thought experiments to test our intuitions relatively to borderline cases of arthood (Danto, 1981). For the moment, of course, philosophers of art have used these thought experiments only to test their own intuitions. In order to investigate the intuitive concept of art from a psychological perspective, a first step would be to use these thought experiments to test the intuitions of various groups of subjects of different social and cultural origins.

At the second level of investigation, much more work is needed to clearly frame the work expected from cognitive approaches. Cognitive approaches may, for instance, help to understand why some ideas about what art is have been more easily integrated than others by a given culture (the general paradigm for this branch of research could be, for instance, the epidemiological approach presented in Sperber, 1996).

\section{Conclusion: a Pluridisciplinary Investigation of Art.}

I have suggested that cognitive approaches to art frequently suffer from a kind of nonspecificity: they focus on a phenomenon which, despite the fact that it can be elicited by some artworks, does not inform our understanding of art in general, or does not clearly do so. It is necessary to solve this problem without falling into essentialisation, i.e. without claiming, implicitly or explicitly, that the phenomenon in question is the real "essence of art". This has forced us to address a difficult question: What is art? The discussion of this question allowed us to distinguish among three different possible topics of investigations for the cognitive approaches : (1) the properties of the things that we call 'artworks', (2) the intuitive categorization of something as art and (3) the reflective justifications concerning the arthood of a thing. 
One difficulty at the first level of investigation is to choose the right object, since the set of things that we call "art” does not coincide with a natural kind which could be investigated scientifically. I suggested the 'relevant' objects of investigation for cognitive approaches of art at this first level are determined by two criteria. The first is trivial: the object of study must be sufficiently circumscribed to be a potential object for scientific investigation (this exclude, for instance, art as such, and possibly also aesthetic experience or the evaluation of artworks). The second criterion is that the object must have the potential to enrich our actual relation with art, through the enrichment of our experience of some artworks and/or the way we converse and think about art and artworks. One way to satisfy this second criterion is to take inspiration from the traditional literature and, more precisely, from theories explicitly concerned with our real relations with art. The simultaneous application of the two criteria would thus amount to finding in traditional theories concerned with our real relation with art those points that can be the object of and benefit from a cognitive perspective.

At the second level of investigation - the intuitive categorization of something as art cognitive approaches could adapt the method they use to investigate moral intuitions. The material for experiments could be directly inspired from the classical thought experiments in analytic philosophy of art. On the one hand, this method provides a radically new perspective on very traditional questions for the analytic philosophy of art. On the other hand, it could provide to cognitive approaches new material, already richly analyzed by other disciplines, to explore the psychological structure on which concepts are built. The last topic - the way people build arguments when discussing the arthood of thing - is extremely vast, and much more work is needed to subdivide it into more circumscribed topics, and understand what kind of contribution could be expected from cognitive approaches. I have suggested that an epidemiological approach could help to describe the feed-back effects of theoretical work on the folk notion of art.

\section{Acknowledgment}

I would like to thank Roberto Casati, Valeria Giardino and two anonymous referees for helpful comments on earlier versions of this paper.

\section{References}

Baxandall, M. (1985) Patterns of intention: on the historical explanation of pictures. New Haven : Yale University Press.

Bell, C. (1915). Art (Revised ed.). London: Chatto and Windus.

Bloom, P. (1996). Intention, history, and artifact concepts. Cognition, 60(1), 1-29. 
Carroll, N. (1999). Philosophy of art: a contemporary introduction. London: Routledge.

Carroll, N. (1993). Historical narratives and the philosophy of art. The Journal of Aesthetics and Art Criticism 51 (3), 313-326.

Casati, R. (2003) Methodological issues in the study of the depiction of cast shadows. A case study in the relationships between art and cognition. Journal of Aesthetics and Art Criticism, 62(2), 163-174.

Casati, R., \& Pignocchi, A. (2007). Mirror and canonical neurons are not constitutive of aesthetic response. Trends in Cognitive Sciences, 11(10), 410.

Casati, R. (2009). Book review: The Art Instinct, by Denis Dutton. [electronic version].

Retrieved http://www.cognitionandculture.net/index.php?option=com content\&view=article\&id=446:book-review-the-art-instinct-by-denisdutton\&catid=63:book-reviews\&Itemid=34

Casler, K. \& Kelemen, D. (2005). Young children's rapid learning about artifacts. Developmental Science, 8, 472-480.

Cavanagh, P. (2005) The artist as neuroscientist. Nature, 434, 301-307.

Cavanagh, P. (1999). Pictorial art and vision. In Robert A. Wilson and Frank C. Keil (Eds.), MIT Encyclopedia of Cognitive Science, (pp. 648-651) Cambridge, MA: MIT Press.

Collingwood, R. G. (1938). The principles of art. Oxford: Clarendon Press.

Danto, A. C. (1981). The transfiguration of the commonplace: a philosophy of art. Cambridge, Mass: Harvard University Press.

Dickie, G. (1969). Defining Art. American Philosophical Quarterly, 6(252).

Dutton, D. (2008). The Art Instinct: Beauty, Pleasure, \& Human Evolution. Bloomsbury Publishing PLC.

Dissanayake, E. (1992). Homo Aestheticus: Where Art Comes From and Why. New York: Free Press.

Freedberg, D., \& Gallese, V. (2007). Motion, emotion and empathy in esthetic experience. Trends in Cognitive Sciences, 11(5), 197-203.

Frith, C. D., \& Frith, U. (2006). The Neural Basis of Mentalizing. Neuron, 50(531-534).

Gaut, B. (2000). Art' as a Cluster Concept. in Theories of art today ed. Noel Carroll University of Wisconsin Press.

Greene, J. \& Haidt, J. (2002). How (and where) does moral judgment work? Trends in Cognitive Science, 6, 517-523

Greene, J., Morelli, S. A., Lowenberg, K., Nystrom, L. E. \& Cohen, J. D. (2008). Cognitive load selectively interferes with utilitarian moral judgment. Cognition 107 (3), 11441154.

Hauser, M. D., Cushman, F., Young, L., Jin, R. K.-X. \& Mikhail, J. (2007). A dissociation between moral judgments and justifications. Mind \& language 22(1), 1-21.

Hyman, J. (2006). Art and Neuroscience [Electronic Version]. Art and Cognition workshop. Retrieved http://www.interdisciplines.org/artcognition/papers/15.

Kaufman, D. A. (2002). Normative Criticism and the Objective Value of Artworks. Journal of Aesthetics and Art Criticism, 60(2), 151-166.

Kennick, W. E. (1958). Does Traditional Aesthetics Rest on a Mistake? Mind, 67, 317-334.

Levinson, J. (1979). Defining art Historically. The British Journal of Aesthetics 19(3), 232250.

Malt, B.C. \& Sloman, S.A. (2007). Category essence or essentially pragmatic? Creator's intention in naming and what's really what. Cognition, 105, 615-648.

Michaud, Y. (1999). Critères Esthétiques et Jugement de Goût. Rayon Art: Jacqueline Chambon.

Pignocchi, A. (2010). How the intentions of the draftsman shape perception of a drawing. Consciousness and Cognition, doi:10.1016/j.concog.2010.04.009 
Ramachandran, V. S., \& Hirstein, W. (1999). The science of art: a neurological theory of aesthetic experience. Journal of Consciousness Studies, 6, 15-51.

Ramachandran, V. S. (2002). The neurological basis of artistic universals [Electronic Version]. Art and Cognition workshop. Retrieved http://www.interdisciplines.org/artcog/papers/9/version/original

Rollins, M. (1999). Pictorial representation: when cognitive science meets aesthetics. Philosophical Psychology, 12, 387-413.

Rollins, M. (2004) What Monet Meant: Intention and Attention in Understanding Art. The Journal of Aesthetics and Art Criticism, 62, 175-188.

Schaeffer, J.M. (1992). L'Art de l'Age Moderne. Nrf essais: Gallimard.

Schaeffer, J.M. (1996). Les Célibataires de l'Art. Pour une Esthétique sans Mythes. Nrf essais: Gallimard.

Sperber, D. (1996). Explaining culture: A naturalistic approach. (Oxford: Blackwell).

Solso, R. L. (2005). The Psychology of Art and the Evolution of the Conscious Brain. MIT Press.

Solso, R. L. (1994). Cognition and the Visual Arts. Cambridge, MA: MIT Press.

Tolstoi, L. N. (1899). What is art? (A. Maude, Trans. 3rd ed.). London.

Walton, K. (2007). Aesthetics - What?, Why?, and Wherefore? Journal of Aesthetics and Art Criticism, 65(2), 147-161.

Weitz, M. (1956). The Role of Theory in Aesthetics (Vol. 15, pp. 27-35): Blackwell Publishing on behalf of The American Society for Aesthetics.

Wollheim, R. (1987). Painting as an Art. London: Thames and Hudson.

Zeki, S. (1999). Inner Vision: an Exploration of Art and the Brain. Oxford, Oxford University Press. 